\title{
O JOVEM MARX
}

\author{
THE YOUNG MARX
}

Ana Selva Castelo Branco Albinati*

\section{RESUMO}

A recepção da obra de Marx, pelo fato de ter se dado ao arrepio da cronologia na qual foi escrita, e em função das contingências e interesses políticos que se verificaram na apropriação de seu pensamento, trouxe, entre outras consequências, dificuldades ao entendimento da totalidade de sua obra, o que levou a periodizações distintas das fases de sua evolução teórica. A publicação de textos de Marx, referentes ao período anterior à Ideologia alemã, a partir da década de 30 do século XX, trouxe à tona uma abertura para a compreensão mais ampla do pensamento do autor e a discussão sobre a relação entre as chamadas obras de juventude e as obras de maturidade. Nosso interesse é apresentar as características da produção teórica do Marx juvenil, situada no intervalo 1841-1843, período interessante pois nos permite conhecer a sua formação, bem como a sua precocidade em realizar inflexões significativas em seu pensamento. Este momento inclui a sua tese doutoral, Diferenças entre as filosofias da natureza de Demócrito e Epicuro, e artigos publicados nos periódicos Anekdota e Gazeta renana, e seu estudo nos apresenta um Marx pouco conhecido, alinhado ao círculo dos jovens hegelianos de esquerda e esgrimando brilhantemente o potencial crítico do idealismo alemão no desvelamento da irracionalidade da realidade social e política.

PALAVRAS-CHAVE: Jovem Marx. Autoconsciência. Liberdade. Racionalidade. Universalidade.

\section{ABSTRACT}

The reception of Marx's work, due it didn't follow the chronology in which it was written, and in the light of the contingencies and political interests that took place in the appropriation of his thought, brought, among other consequences, difficulties in understanding the totality of his work, which led to different periodizations of the phases of his theoretical evolution. The publication of Marx's texts written prior to the German Ideology, from the 1930s onwards, has brought to the surface the possibility for a broader understanding of the author's thinking and the discussion on the relation between the so-called juvenile and mature Marx's works. Our goal is to present the characteristics of the theoretical production of the juvenile Marx, located in the interval 1841-1843, an interesting period as it allows us to know Marx's formation, as well as his precocity in realizing significant changes in his thought. This time includes his doctoral thesis, Differences between Democritus' and Epicurus'philosophies of nature, and articles published in the Anekdota and Gazeta Rhenian periodicals. By studying it, we are presented with a little-known Marx, aligned with the circle of the young left Hegelians and wielding brilliantly the critical potential of German idealism in unraveling the irrationality of social and political reality.

KEYWORDS: Young Marx. Self-consciousness. Freedom. Rationality. Universality.

\footnotetext{
*Doutora. Professora do Departamento de Filosofia da PUC Minas. E-mail: anaselvaalbinati@gmail.com.
} 


\section{INTRODUÇÃO}

A recepção da obra de Marx, pelo fato de ter se dado ao arrepio da cronologia na qual foi escrita, e em função das contingências e interesses políticos que se verificaram na apropriação de seu pensamento, trouxe, entre outras consequências, dificuldades ao entendimento da totalidade de sua obra, o que levou a periodizações distintas das fases de sua evolução teórica.

A publicação de textos de Marx, referentes a seu período anterior à Ideologia alemã, a partir da década de 30 do século XX, traz à tona uma abertura para a compreensão mais ampla do pensamento do autor e abre, por sua vez, a discussão sobre a natureza teórica do conjunto da obra de Marx, que se instaurou em função da compreensão da ligação entre as chamadas obras de juventude e as obras de maturidade. Em torno dessa discussão, os intérpretes farão a partilha da obra de Marx, ficando alguns com o jovem Marx em detrimento do velho Marx, outros rechaçando o jovem Marx em função do Marx maduro. O conhecimento do que veio a se denominar "obra de juventude" teve, como consequência, trazer à tona um Marx até então desconhecido, com o que se instaurou uma polêmica acerca do que seria o "verdadeiro Marx". Em meio a essa discussão, dois nomes se destacam, Louis Althusser e Gyorg Lukács.

De acordo com Althusser, a obra de Marx deve ser dividida em dois momentos, aquele que constitui o seu período de juventude, que se estenderia até 1845-46, quando da elaboração de $A$ ideologia alemã, texto que marca a passagem para a produção de maturidade do autor. Mais que separar esses dois momentos, Althusser entende como necessária a recusa do período inicial de Marx considerando-o como um período marcado por um humanismo preso às categorias da filosofia tradicional que, em última análise, expressariam a concepção burguesa de mundo. Assim, Althusser dirá que o período até 1845 pode ser subdividido em dois momentos: "o do humanismo racionalista-liberal, mais próximo de Kant e Fichte do que de Hegel", que se encontra fundamentalmente nos artigos da Gazeta Renana, e o do "humanismo comunitário de Feuerbach" (ALTHUSSER, s/d, p.16-17), que se expressa sobretudo nos $M a$ nuscritos econômico-filosóficos.

No primeiro caso, a referência aos artigos da Gazeta Renana destaca a compreensão de Marx naquele momento, no qual "a liberdade é a essência do homem como o peso é a essência dos corpos" (p. 15) e no qual "o homem apenas é liberdade ao ser razão" (p. 16). A segunda etapa, que se estenderia de 1842 a 45, se caracteriza, segundo Althusser, pelo tratamento do homem como ser genérico, no qual "mais uma vez aqui a essência do homem fun- 
damenta a história e a política" (p. 18-19). Seria a partir de A ideologia alemã, que Marx romperia "radicalmente com toda a teoria que fundamenta a história e a política numa essência do homem" (p. 20), ruptura que, no entendimento de Althusser, comporta três aspectos teóricos indissociáveis:

1. Formação de uma teoria da história e da política baseada em conceitos radicalmente novos: conceitos de formação social, forças produtivas, relações de produção, superestrutura, ideologias, determinação em última instância pela economia, determinação específica dos outros níveis, etc.

2. Crítica radical das pretensões teóricas de todo e qualquer humanismo filosófico.

3. Definição do humanismo como ideologia. (ALTHUSSER, s/d, p. 20)

A ruptura com a filosofia idealista e com a antropologia feuerbachiana inaugura uma nova problemática na compreensão da relação entre sociedade e indivíduo, marcada por novos conceitos de caráter não mais filosófico-humanistas, e sim científicos. A partir dessa compreensão de um corte epistemológico que perpassa a obra de Marx, Althusser advoga o abandono definitivo de sua proposição de juventude, porque a depuração dos elementos idealistashumanistas é uma condição para o conhecimento científico das relações sociais e para a sua transformação.

Por outro lado, Gyorg Lukács identifica uma unidade no pensamento de Marx, de forma que o reconhecimento de novas categorias de análise que passam a fazer parte do aparato conceitual do autor é tido como um amadurecimento que não romperia com a perspectiva inicial de Marx. Essa abordagem lukacsiana da continuidade não é isenta de problemas, e um deles seria a consideração de que, mesmo em textos iniciais de Marx, como a sua tese de doutorado, já estariam presentes, ainda que em germe, as questões e encaminhamentos que se desdobrariam em sua obra de maturidade. Assim, Lukács (2009, p. 126) afirmará em O jovem Marx, que "entre 1840 e 1841, já estava presente nele o núcleo da posterior superação crítica da filosofia hegeliana".

Se a proposição lukacsiana nos parece mais pertinente, é importante ressaltar que mesmo esse grande intérprete de Marx não aponta claramente a diferença da natureza teórica que se observa na evolução do pensamento marxiano. Lukács não toma o devido cuidado em diferenciar o primeiro Marx - aquele da tese doutoral e dos artigos da Gazeta Renana -, no que se refere à natureza teórica, dos textos que virão a seguir e que se orientam no sentido da ruptura de Marx com a tradição idealista alemã. Embora a identificação da matriz idealista presente nos escritos de Marx no período de 1841 a 1843 seja ponto pacífico entre intérpretes, 
não se tem, por outro lado, um entendimento consensual acerca da relação desse momento com a continuidade da sua produção teórica, e no que é fundamental, nenhum desses intérpretes frisou a radicalidade da inflexão que se observa na obra de Marx a partir de seu ponto de ruptura, que se dá com a redação da Crítica da filosofia do direito de Hegel, de 1843.

A esse respeito, José Chasin afirma que a ruptura marcante na obra de Marx se dá entre seu curto período pré-marxiano e aquele outro a partir do qual o autor se concentra numa investigação de natureza teórica radicalmente distinta do primeiro. Assim, os textos que vão de 1841 a 1843 é o período propriamente juvenil. Em meados de 1843, a redação da Crítica da filosofia do direito de Hegel marca a transição para o período de ruptura com o idealismo alemão e elaboração de seu pensamento próprio, cuja maturidade é atingida na segunda metade da década de 50, quando de suas formulações abrangentes acerca da relação entre a economia e a sociabilidade.

A característica do período juvenil de Marx é sua pertença à filosofia da autoconsciência. Como analisa Chasin:

\begin{abstract}
A autoconsciencialidade, como base e atmosfera, se estende pelos artigos da Gazeta Renana, o conjunto dos quais expressa com abundância e muita nitidez os traços marcantes do pensamento político pré-marxiano de Marx. Aliás, enquanto tal, sejam quais forem as divergências interpretativas que tenham ocorrido, esse é um capítulo, no fundamental, exegeticamente pacífico, inclusive no reconhecimento de sua grande relevância para o rumo futuro da orientação teórica do autor. Não, grife-se com toda força, porque contenha algum elemento germinal do itinerário posterior, mas, ao contrário, porque levou Marx, a partir de um dado momento, ao questionamento e abandono subsequente de todo o complexo teórico em que, até então, inseria sua reflexão. (CHASIN, 2009, p. 49).
\end{abstract}

Nosso interesse é apresentar esse Marx juvenil, o dos primeiros escritos que se encontram no intervalo 1841-1843, período interessante porque nos permite conhecer a sua formação, bem como a sua precocidade em realizar a inflexão definitiva em seu percurso teórico. Este período inclui a sua tese doutoral, de 1841, alguns poucos artigos publicados no periódico Anekdota e os artigos da Gazeta Renana, jornal do qual foi redator-chefe, até meados de 1843.

\title{
1 MARX À ÉPOCA DA TESE DOUTORAL
}

Diferença entre a filosofia da natureza de Demócrito e a de Epicuro é o título da tese de doutoramento de Marx, defendida em 1841, quando tinha apenas 23 anos. Esse trabalho foi 
encontrado incompleto, mas mantém sua importância tanto no que se refere à abordagem original de Marx da filosofia pós-aristotélica, quanto no que oferece de revelador em relação às inquietudes do jovem Marx frente ao seu tempo e à filosofia que se segue ao pensamento hegeliano.

Nesse curto período de sua vida, o jovem Marx participou do grupo dos pensadores neo-hegelianos de esquerda que, a partir da apropriação dos aspectos revolucionários do pensamento de Hegel, deram início ao chamado "idealismo ativo". Entre esses, Bruno Bauer, que teria dado a sugestão do tema de estudo a Marx. O interesse do autor pelas escolas pósaristotélicas se dá pelo reconhecimento de que, em seu conjunto, elas contêm a "construção completa da autoconsciência”, questão cara ao idealismo ativo. Observa Marx (2018, p. 31):

\footnotetext{
Parece-me que, ao passo que os sistemas mais antigos são mais significativos e mais interessantes pelo conteúdo, os pós-aristotélicos - sobretudo o ciclo das escolas epicurista, estoica e cética - o são pela forma subjetiva, pelo caráter da filosofia grega. Só que, até agora, justamente a forma subjetiva, suporte espiritual dos sistemas filosóficos, foi quase totalmente esquecida em função de suas determinações metafísicas.
}

Ao contrário das considerações tradicionais na história da filosofia que relegam esses sistemas filosóficos a um segundo plano, e mesmo a "um suplemento quase inconveniente" (MARX, 2018, p. 29) da filosofia aristotélica, Marx os compreende como passíveis de uma real compreensão apenas na modernidade: "Só agora chegou a época em que será possível entender os sistemas dos epicuristas, dos estoicos e dos céticos. Trata-se da filosofia da autoconsciência” (MARX, 2018, p. 25).

Tal projeto não teve o desenvolvimento previsto, tendo o autor se limitado ao estudo da relação entre a física de Demócrito e a física de Epicuro, instigado pela questão de como esses pensadores poderiam ser personalidades tão distintas entre si e apresentar compreensões da realidade tão diferenciadas, se ambos partiam do mesmo princípio, o atomismo. Analisando a concepção de átomo nos dois autores, Marx será capaz de reconstruir dois blocos filosóficos distintos, sistemáticos e coerentes, num trabalho notável de escavação dos princípios.

Distinguindo em traços largos as duas filosofias, na primeira parte da tese, Marx nos revela um Demócrito angustiado e cético e um Epicuro dogmático e satisfeito, traços de personalidades compreensíveis a partir da maneira como concebiam a realidade e o conhecimento. Na segunda parte, Marx adentra nas diferenças específicas na concepção dos átomos, de tal forma a contestar a leitura consolidada do epicurismo como um mero plágio da filosofia de 
Demócrito, que não traria maiores contribuições e que, inclusive, deturparia o modelo original. Nesse empenho, traz à luz os elementos distintivos do pensamento de Epicuro, cujo coroamento é a afirmação da autoconsciência como princípio supremo.

A questão em foco é a da relação entre autoconsciência e mundo, questão que no idealismo ativo recebe um tratamento que privilegia a autoconsciência como elemento que reclama o princípio da razão contra a positividade do real. Nesse sentido, o interesse por Epicuro pode ser compreendido por ser o autor que, ao trabalhar a contraditoriedade do átomo em sua determinação natural, a queda em linha reta, e em sua autodeterminação, através do movimento da declinação, introduziria a liberdade na própria natureza, contrapondo-se ao materialismo mecanicista de Demócrito. A afirmação da declinação como "alma do átomo" é o conceito da particularidade abstrata. Ela é o princípio da autonomia que, ao se contrapor ao movimento da queda em linha reta, possibilitaria o encontro dos átomos e a formação do mundo.

A diferença patente em relação ao atomismo de Demócrito é que a necessidade afirmada por este abre espaço para o acaso e para a vontade na filosofia epicurista. À medida que o movimento da declinação, introduzido por Epicuro, permite a passagem da necessidade à liberdade, também fica garantido o trânsito da física à ética, questão cara aos jovens hegelianos de esquerda.

No entanto, a autodeterminação não reina sozinha e, para que se dê o encontro dos átomos e a constituição do mundo, é necessário considerar o princípio material, a determinação natural da queda em linha reta. Donde a realização da declinação, ao ser posta em termos positivos, se dá em meio também à necessidade e ao acaso, de modo que "estão sinteticamente reunidas, portanto, a materialidade deles, da queda em linha reta, e sua determinação formal, posta na declinação" (MARX, 2018, p. 82).

Exposta a diferença fundamental dos princípios do atomismo de Demócrito e de Epicuro, salientam-se dois aspectos na filosofia epicurista: a apreensão da "alma contraditória" do mundo e a emergência da autoconsciência como princípio de todas as coisas. O primeiro aspecto será mais aprofundado na análise das qualidades dos átomos e na compreensão de Epicuro da contraditoriedade do átomo como princípio e como elemento material, cuja realização da essência é "degradada à condição de matéria absoluta, de substrato amorfo do mundo fenomênico" (MARX, 2018, p. 101). Acrescente-se a esse desenvolvimento a análise do tempo como o elemento devorador do fenômeno, que nos revela a essência. Tudo isso faz com que Marx reconheça Epicuro como "o primeiro a conceber a manifestação como mani- 
festação, isto é, como estranhamento da essência, sendo que ela própria se torna atuante em sua realidade como tal estranhamento" (MARX, 2018, p. 105).

O segundo aspecto é mais bem determinado no capítulo sobre os meteoros, quando Marx encontrará desnudado o princípio da autoconsciência como o fundamento da filosofia epicurista. Isso porque é ali que Epicuro, ao contrariar toda a tradição grega no que se refere à perfeição dos corpos celestes, o faz no propósito de afirmar a supremacia da autoconsciência. A autoconsciência se manifesta na contradição entre essência e existência. Não existindo essa contradição, haveria uma conciliação entre autoconsciência e mundo, com a absorção da primeira pelo segundo, abrindo caminho para o misticismo e o enlevo especulativo. Segundo Marx, é como se, nesse momento, o princípio da autoconsciência se afirmasse plenamente na teoria de Epicuro. Ele leva até as últimas consequências uma consciente oposição da individualidade abstrata à universalidade. Essa autoconsciência, instalada na natureza do átomo pela declinação, seria caracterizada posteriormente por Lucrécio como "aquele algo em seu âmago que é capaz de contra-atacar e resistir” (MARX, 2018, p. 76).

Não se pode deixar de trazer essas escavações do autor para o seu próprio tempo, e situá-lo em meio aos debates de sua época. Ele se refere ao helenismo como sendo uma época titânica, de separação, sem conciliação entre a filosofia e a realidade. Nesse contexto, a única ventura é o fato de que essas filosofias se voltem contra a positividade do real. Em seus cadernos de anotações, Marx dirá de uma "necessidade histórica" que permite a compreensão de como, depois de Aristóteles, pode sair à luz um Epicuro. A ruptura da pólis e da totalidade ética explica por que "as filosofias epicurista e estoica foram a ventura de seu tempo; assim como a mariposa noturna, que busca a luz da lâmpada particular quando já se pôs o Sol universal" (MARX, 1987, p. 132).

Ao se referir a essa época, o que ele tem em vista é o seu próprio tempo. Nas notas ao capítulo IV da primeira parte, referindo-se à cisão entre os discípulos de Hegel, ele dirá de duas tendências que se opõem, a liberal e a positiva:

A primeira retém como determinação principal o conceito e o princípio da filosofia, enquanto a outra retém como tal seu não conceito, o fator da realidade. Essa segunda tendência é a filosofia positiva. O ato da primeira é a crítica e, portanto, exatamente o voltar-se para fora da filosofia, sendo o ato da segunda a tentativa de filosofar e, portanto, o voltar-se para dentro de si da filosofia, ao tomar ciência da deficiência como algo imanente à filosofia, ao passo que a primeira a compreende como deficiência do mundo a ser tornado filosófico. (MARX, 2018, p. 58-59). 
Tomando partido pela tendência liberal, Marx não deixa, entretanto, de apontar as suas limitações, quando cinde a totalidade do sistema hegeliano, e unilateraliza o papel da autoconsciência.

Embora se discuta muito a relação de Marx com Hegel nesse momento, o que se percebe claramente é a refutação da história da filosofia apresentada por Hegel, a partir da contraposição da leitura acerca de Epicuro, valorizando neste os aspectos criticados por Hegel, quais sejam, o abandono da teologia e da teleologia em prol da liberdade da vontade, a modalidade em que a filosofia se comporta como consciência subjetiva frente à realidade. No entanto, tendo como referência a categoria de totalidade, herdeira do hegelianismo, o que encontramos em sua tese doutoral são indicações elogiosas do procedimento epicuriano de confrontação da necessidade, ao mesmo tempo que indicações críticas do princípio da particularidade abstrata que se comporta frente à objetividade como uma exterioridade.

Ao tratar da duplicidade do átomo como princípio, existindo no vácuo, e do átomo como elemento, existindo na realidade, Marx afirma a respeito do procedimento de Epicuro:

Como seu princípio é o átomo, também o modo de seu conhecimento é atomista. Cada momento do desenvolvimento de imediato se transforma sub-repticiamente em uma realidade fixa, separada do contexto como se fosse pelo espaço vazio; toda determinação assume a forma de uma particularidade isolada. (MARX, 2018, p. 99).

A referência às limitações da compreensão atomística da realidade evidencia a presença do pensamento hegeliano nesse momento da produção de Marx. Em sua lógica, Hegel dirá a respeito do procedimento atomístico:

A filosofia atomística é esse ponto de vista em que o absoluto se determina (a si mesmo) como ser-para-si, como Uno, e como muitos Unos. Como sua força fundamental, admitiu-se também a repulsão, que se revela no conceito do Uno; porém não é atração, mas o acaso, isto é, o carente-de-pensamento, que deve reuni-los. Fixando-se o Uno como Uno, seu encontrar-se junto com outros deve ser visto como algo totalmente exterior. (HEGEL, 2005, p.196).

O interesse de Marx por Epicuro é revelador já de uma certa tensão em relação ao pensamento hegeliano, bem como a de seus herdeiros com os quais convivia. Se se afasta de Hegel ao recuperar a originalidade e superioridade do pensamento de Epicuro frente a Demócrito, e acentuar a importância das filosofias pós-aristotélicas, por outro lado aponta as limitações do pensamento atomístico que rompe com as noções de totalidade e desenvolvimento. 
Esse aspecto é significativo na avaliação da relação Marx-Hegel, porque a repulsão em Epicuro se expressa não só na composição dos átomos na natureza, mas também na amizade e no contrato, ou seja, a constituição política é vista atomisticamente, como algo exterior.

A indicação, por diversas vezes repetida, do caráter da autoconsciência em Epicuro traz em si, a despeito do tratamento elogioso que ele dispensa ao filósofo, o reconhecimento da limitação de tal conceito. Ele dirá, por exemplo, numa passagem a respeito da distinção que Epicuro faz entre o átomo-princípio e o átomo- matéria:

Quando o átomo é pensado segundo seu conceito puro, o espaço vazio, a natureza aniquilada, é sua existência; pois prossegue para a realidade, desce à condição de base material, que, sendo portadora de um mundo de múltiplas relações, jamais existirá a não ser em suas formas indiferentes e exteriores. Essa é uma consequência necessária porque o átomo, pressuposto como algo abstratamente individual e pronto, não é capaz de operar como poder idealizador e abrangente daquela multiplicidade. "A particularidade abstrata é a liberdade da existência, não a liberdade na existência" (MARX, 2018, p. 102).

Se atentarmos a esse trecho, temos que o entendimento do átomo enquanto particularidade abstrata só pode desembocar numa atitude de negação do existente, decorrente do reconhecimento da contraditoriedade de sua alienação no existente, diante do qual só resta o desvio, a ataraxia. É a isso que ele se refere ao dizer que a "particularidade abstrata é a liberdade da existência, não a liberdade na existência", ou seja, é a liberdade de se abstrair da existência, mas não de se reconhecer como liberdade realizada na existência.

Nessa citação reconhecemos de forma inequívoca a tematização hegeliana da relação particular-universal. A linguagem de Marx se aproxima imensamente da de Hegel que afirma a propósito da consciência estoica, o que vale no caso também para a consciência epicurista: "A liberdade no pensamento tem somente o puro pensamento por sua verdade, e verdade sem a implementação da vida. Por isso é ainda só o conceito da liberdade, não a própria liberdade viva" (HEGEL, 1992, p. 136).

Essa caracterização da particularidade abstrata feita por Marx nos remete à sua intenção inicial que era fazer um estudo da filosofia helenística. Como tal projeto não se completou, não há elementos que possam indicar, com certeza, o rumo pelo qual Marx encaminharia a questão da autoconsciência a partir do epicurismo. José Américo Pessanha (s/d. p. 13) observa a esse respeito: 
Ao escrever a tese sobre os materialistas antigos, Marx reconhece que a liberdade alcançada no epicurismo é aquela possível numa filosofia da autoconsciência: uma liberdade somente interior. É a liberdade compatível com uma filosofia do indivíduo isolado, da declinação do átomo - e que se amplia apenas até às dimensões da solidariedade dos pequenos grupos privilegiados pela sabedoria, às dimensões da serena e prazerosa amizade, como na confraria do Jardim de Epicuro ou do Doktorklub.

A tese doutoral suscita ainda hoje ricas polêmicas quanto ao seu lugar na obra de Marx. Alguns intérpretes viram nesse texto uma primeira aproximação de Marx com o materialismo. É, por exemplo, a posição de Denis Collin, em Epicuro e a formação do pensamento de Karl Marx, que sugere que a tese seria o ponto de partida para o materialismo de Marx. Também John Bellamy Foster, em A ecologia de Marx: materialismo e natureza, acredita que a crítica materialista de Hegel já está presente na tese, à qual se sobrepôs posteriormente a influência de Feuerbach. Mesmo György Lukács, em O jovem Marx, identifica na tese doutoral os germes do que seria o pensamento do autor, pois já se encontraria ali o intento de descobrir e superar as insuficiências do hegelianismo. Já Auguste Cornu, em Del idealismo al materialismo histórico, e Mario Rossi, em La génesis del materialismo histórico, sustentam, a nosso ver, de forma correta, o caráter idealista da análise que Marx faz do materialismo epicurista.

Como observa Cornu (1965, p. 151) a respeito do idealismo em Marx:

O idealismo, cujo princípio é a autonomia absoluta do espírito, constituía a tal ponto para ele o verdadeiro fundamento da ciência que considerava mérito de Epicuro a formulação verdadeira da teoria do átomo, ao distinguir a essência da substância e subordinar o elemento material ao espiritual, com o que superou o materialismo determinista de Demócrito.

No entanto, enquanto Cornu sublinha o avanço que Marx realiza ali em relação aos limites do pensamento especulativo e de seu desdobramento no neo-hegelianismo de esquerda, Rossi assume uma cautela maior na avaliação do texto, pois o projeto original se encontra incompleto, o que compromete a elucidação da posição do autor frente ao idealismo.

A nosso ver, Marx parece se mover, a um só tempo, em meio à recusa do reconhecimento do real como racional a partir de Hegel, e ao questionamento da efetividade da particularidade abstrata em sua relação com o mundo a partir de Epicuro. Ele encontra no epicurismo o germe dessa consciência que deve ser elevada a juiz do mundo. Porém, critica a forma atomística como é pensada a subjetividade e a objetividade como determinações abstratas uma em relação à outra. Como não temos a continuidade do estudo da estrutura completa da auto- 
consciência, o que nos resta como elemento para a compreensão do pensamento do autor e sua relação com a filosofia hegeliana são os textos imediatamente posteriores à tese, os artigos da Gazeta Renana.

\section{MARX COMO REDATOR DA GAZETA RENANA}

Ao término de sua tese doutoral, Marx encontra-se diante da impossibilidade de uma carreira acadêmica, em virtude do momento político antiliberal de Frederico Guilherme IV. Em vista dessa situação, inicia sua colaboração no periódico Gazeta Renana, no período de 1841 a meados de 1843, assumindo a sua direção de redação em outubro de 42. Além disso, colaborou com o periódico de Arnold Ruge, a Anekdota, com dois artigos publicados em fevereiro de 42, "Lutero, árbitro entre Strauss e Feuerbach" e "Observações sobre a recente instrução prussiana acerca da censura”. Os artigos que aqui serão tratados fazem parte da coletânea dessas duas publicações.

A reflexão de Marx permanece no interior do idealismo, e mais precisamente, do idealismo ativo, marcado pela ênfase à autoconsciência. É possível encontrar também fortemente nos artigos a presença de referências diretas e indiretas a Kant e Fichte, no que diz respeito à origem racionalista da liberdade e de suas manifestações, derivando dessa forma os costumes, as tradições, as instituições, do caráter legislador da razão humana. Em seus artigos, que compreendem uma gama ampla de assuntos sobre tramitações de leis, censura na imprensa, assuntos relativos ao Estado, ele exerce o objetivo do idealismo ativo, qual seja, a invocação da filosofia como resgate dos fundamentos sobre os quais se deve pensar as instituições, os costumes e as leis, de forma a reclamar a racionalidade que deve se externar nesses fenômenos sociais. A essa época, seu pensamento se inclui na tradição idealista que considera o Estado como o "Estado da universalidade humana", instância na qual se expressa e se preserva a liberdade humana. Da mesma forma, o direito é visto como uma esfera da racionalidade e da imparcialidade, de tal forma que, nos artigos, Marx se posiciona a partir da ideia de direito racional para cobrar a racionalidade do direito positivo. Tal posicionamento se torna claro, por exemplo, em um dos artigos sobre a liberdade de imprensa:

\footnotetext{
As leis não são medidas repressivas contra a liberdade, da mesma forma que a lei da gravidade não é uma medida repressiva contra o movimento, já que , enquanto lei de gravitação, impulsiona precisamente os movimentos dos astros, ainda que, como lei que rege a queda dos corpos, se volte contra mim quando atento contra ela, tentando me manter suspenso no ar. As leis são an-
} 
tes as normas positivas, luminosas e gerais onde a liberdade tem uma existência impessoal, teórica e independente da vontade particular. Um código de leis é a bíblia da liberdade de um povo. (MARX, 1987, p. 200-201).

Localizando essa determinação conceitual da lei como expressão positiva, objetiva da liberdade, Marx critica a compreensão positiva da realidade, na qual o existente vale por si mesmo, sem uma legitimidade advinda do fato de corresponder à sua determinação essencial. Dessa forma há leis existentes que não correspondem ao conceito de lei, enquanto há, por outro lado, leis que ainda não revestem a forma de lei, mas que por direito, deveriam sê-lo.

De acordo com a argumentação de Marx, somente a partir do ponto de vista da liberdade como essência do espírito humano é que é possível distinguir o empírico, o positivo, do que é legal, do que tem direito universal à existência. A esse respeito, segue-se o comentário do autor:

\footnotetext{
A lei de imprensa é, portanto, o reconhecimento legal da liberdade de imprensa. É direito, porque é a existência positiva da liberdade. Tem, portanto, que existir necessariamente, ainda que nunca se aplique, como ocorre na América do Norte, enquanto que a censura, como a escravidão, não podem nunca ser legais ainda que sejam registradas mil e uma vezes na forma de lei. (MARX, 1987, p. 201).
}

Nesse período, a fundamentação racional do direito é convocada para contrastar o direito positivo. Da mesma forma, o Estado é tido por Marx como a expressão maior da universalidade do gênero humano. O Estado é a expressão consciente da liberdade que nos indivíduos existiria apenas inconscientemente, de maneira natural, cabendo à educação pública a elevação dos indivíduos de sua naturalidade à sua vida civil. Essa determinação do Estado por vezes se confronta com a manifestação positiva de um determinado governo. É dentro desse entendimento que Marx se encontra quando identifica o descompasso entre essa determinação de Estado e a sua realização enquanto governo no corpo administrativo do Estado, que se comportaria de acordo com seus interesses particulares e não imbuído do espírito público requerido para tal função.

Ele se encontra, portanto, no interior do entendimento tradicional da política como o elemento por excelência de realização da universalidade humana. A citação seguinte acerca do Estado, retirada do artigo “O Editorial do número 179 da Gazeta de Colônia” tratará de apagar qualquer dúvida contrária a este entendimento: 
Se os primeiros filósofos do Direito Público derivaram o Estado partindo dos impulsos da ambição ou do instinto social, ou partindo também da razão, não porém da razão da sociedade, e sim da razão do indivíduo, o ponto de vista mais ideal e mais fundamentado da novíssima filosofia o derivam partindo da ideia do Todo. Considera o Estado como o grande organismo em que deve realizar-se a liberdade jurídica, moral e política e em que o cidadão singular do Estado obedece nas leis deste somente a sua própria razão, a razão humana. (MARX, 1987, p. 236).

Pode-se depreender desse trecho a determinação do Estado como organismo no qual cada indivíduo reconhece sua própria razão enquanto razão humana, universal, e não propriamente de forma individualizada, ao sabor das contingências que porventura possam justificar uma "razão do indivíduo". Acompanhando Hegel, Marx rejeita as teorias de um contrato social, advindo de um acordo exterior entre os indivíduos. Mas diferentemente de Hegel, não concebe o Estado como ápice do movimento do Espírito objetivo, e sim aponta a fundamentação do Estado na própria natureza humana. A razão do Estado está em ser a expressão maior da natureza humana, e nesse aspecto, aproxima-se mais da tematização kantiana. De toda forma, o Estado é caracterizado não como uma aglomeração de interesses e de unidades particulares, mas como centro de um todo orgânico, no qual cada indivíduo se reconhece enquanto partícipe da razão humana. De acordo com suas palavras no artigo "Sobre a liberdade de imprensa", Marx reconhece nesse momento "os invisíveis fios nervosos que enlaçam o particular e o geral e que, no Estado e em tudo o mais, convertem as partes materiais em membros animados de um todo espiritual" (MARX, 1987, p. 176).

No artigo "O Editorial do n ${ }^{0} 179$ da Gazeta de Colônia” a polêmica em questão é sobre a relação da religião com o Estado. Marx dirige sua crítica a um editorial da Gazeta de Colônia, no qual se acusa a linha progressista do jornalismo assumida sobretudo por Marx, caracterizada pelas críticas aos princípios cristãos do Estado. Em resposta, Marx retoma a concepção do Estado laico, demonstrando a incoerência de, enquanto esfera universal, o Estado assumir os valores de uma religião particular. Isso descaracterizaria o Estado enquanto portador das potencialidades humanas pois limitaria os seus valores aos valores particulares de um grupo especial. Nesse mesmo artigo, o autor articula a filosofia e a política, através da característica peculiar a ambas, que é o fato de se constituírem como expressões universais, cada um a seu modo, da natureza humana.

A filosofia e a política são, neste período para Marx, os momentos respectivamente teórico e prático de um mesmo desenvolvimento do espírito humano na sua busca pelos valores universais. Vejamos por partes: Marx afirma 
ou o Estado cristão corresponde ao conceito de Estado como realização da liberdade racional, e neste caso lhe bastará ser um Estado racional para ser um Estado cristão e bastará desenvolver o Estado partindo das racionalidades humanas, obra que a filosofia leva a cabo. Ou o Estado de liberdade racional não pode desenvolver-se partindo do cristianismo, neste caso vós mesmos reconhecereis que este desenvolvimento não está implícito na tendência do cristianismo, já que este não quer um Estado imperfeito, e o Estado que não seja a realização da liberdade é um Estado imperfeito. (MARX, 1987, p. 235).

Contrasta-se aqui então o cristianismo e a filosofia. A filosofia como a procura da "natureza da sociedade humana" sobre a qual deve se fundar o Estado, numa abrangência que ultrapassa os limites e os valores particulares da "sociedade cristã". Dessa forma, tendo em vista que "a filosofia é a que interpreta os direitos da humanidade, a que exige que o Estado seja o Estado da natureza humana" (MARX, 1987, p. 234), conceber a religião como fundamento do Estado é contradizer essencialmente a determinação do Estado como "realização da liberdade racional".

À filosofia cabe a crítica do existente, no sentido de diferenciar o acidental do essencial, o arbitrário do necessário, o efetivo do verdadeiro, tendo como princípio a universalidade da liberdade como essência humana, para além de qualquer fronteira cultural, geográfica ou religiosa. A esse propósito, Marx se pergunta:

\footnotetext{
Não existe uma natureza humana universal, como existe uma natureza universal das plantas e dos astros? A filosofia não pergunta o que está em vigor, mas sim o que é o verdadeiro, pergunta o que é o verdadeiro para todos os homens e não somente para alguns; suas verdades metafísicas não se detêm ante as fronteiras da geografia política; suas verdades políticas sabem muito bem onde começam as 'fronteiras', podendo trocar o horizonte ilusório de uma concepção particular do mundo e do povo com o verdadeiro horizonte do espírito humano. (MARX, 1987, p. 227).
}

Para o jovem Marx, a filosofia é a arma crítica que responde à exigência de realização da liberdade racional na realidade que se lhe contrapõe, não se deixando iludir pelas formas do existente. A crítica ao Estado prussiano deriva dessa exigência, da mesma forma que a crítica às leis que apenas revestem a forma de leis, mas que não o são verdadeiramente pois não realizam a "liberdade racional".

O pano de fundo da análise de Marx, seja em relação ao Estado, ou em relação às leis, é a suposição de uma natureza humana na qual coexistem racionalidade e liberdade. Essa na- 
tureza ainda inconsciente deve se tornar consciente no Estado, o que se faz através da educação. Assim ele dirá que

\begin{abstract}
a verdadeira educação 'pública' do Estado consiste na sua existência racional e pública; o Estado educa seus membros ao torná-los membros do Estado, ao converter os fins individuais em fins universais, os toscos impulsos em inclinações morais, a independência natural em liberdade espiritual, ao fazer com que o indivíduo se identifique na vida do todo e o todo nas intenções do indivíduo. (MARX, 1987, p. 228).
\end{abstract}

Tal fundamentação racional do Estado e do direito é ainda mais patente na polêmica que Marx trava com a escola histórica do direito, corrente fortemente influenciada pelo romantismo, cujo representante à época era Friedrich Carl von Savigny. Essa corrente supunha o direito como uma manifestação cultural, nascido do "espírito do povo". Tal escola se opunha ao jusnaturalismo que fundamenta o direito na razão natural, posição compartilhada pelo jovem Marx. Savigny foi discípulo de Gustav Hugo, e é a ele que Marx se reporta em sua crítica à visão positiva da Escola histórica do direito.

Marx recupera Kant, contrariamente ao procedimento de Hugo que advoga a legitimidade do existente, da positividade como valendo como critério de valor por si mesma. O núcleo da argumentação de Marx é a proposição kantiana de derivar da racionalidade a necessidade e a universalidade de um determinado costume ou instituição. A não capitulação ante o existente só pode ser encetada por um trabalho crítico no qual se alcance a possível essencialidade de um dado positivo, de forma a desvelar o vínculo de racionalidade que permita ou não legitimá-lo.

No artigo "O manifesto filosófico da Escola Histórica do Direito", Marx questiona o relativismo ético que seria consequência dos pressupostos de tal corrente. A crítica à equivalência das condutas morais está presente quando ele diz que, para Hugo, "o alemão que educa sua filha como a joia da família não é para ele mais positivo que o rasbuta, que a mata para não ter que se preocupar em alimentá-la” (MARX. 1987, p. 238). Essa característica de Marx é própria do idealismo ativo, para o qual a autoconsciência é o juiz que deve medir a existência singular pela essência, o positivo pelo racional.

É ainda em função de sua confiança na vocação universalista da política e de sua crença no Estado da liberdade e da universalidade humana, que ele, em um de seus últimos artigos para a Gazeta Renana, se depara com a questão da legislação acerca do roubo de lenha, que é um dos artigos mais interessantes para se perceber como ele esbarra nos limites desta concep- 
ção idealista. Nesse artigo, Marx chega a tocar na essência do Estado, ao apresentar uma análise do desenvolvimento da lei sobre o roubo de lenha, na qual mostra claramente os laços entre o Estado e o direito e os interesses e privilégios das classes abastadas.

O artigo é muito perspicaz ao constatar a natureza particular que se esconde sob as leis positivas, mas, a despeito desta constatação, Marx afirma a exigência idealista de que o existente deve corresponder ao seu conceito - entendido aqui como produto da universalidade da razão humana -, vendo nesses desvios, perversões contra as quais o remédio suficiente ainda parece ser a crítica filosófica.

A própria designação de roubo para a recolha de lenha por parte dos lenhadores é questionada por Marx, uma vez que esse recolhimento já se constituíra anteriormente em direito consuetudinário dos pobres, muito mais racional que a nova legislação, que o suprime a partir dos interesses particulares dos proprietários de bosques. Essa observação leva Marx a verificar que, historicamente, o que seriam os direitos consuetudinários dos ricos transitam rapidamente ao reconhecimento jurídico na forma de leis positivas, pela interpenetração de interesses privados e públicos que se dá no âmbito do Estado. "Estes direitos encontram na lei, não somente o reconhecimento racional, mas, muitas vezes, o reconhecimento de suas arrogâncias irracionais" (MARX, 1987, p. 255). No entanto, o mesmo não ocorre em relação aos direitos dos pobres, de tal forma que apenas para estes é que os direitos continuam existindo como direitos consuetudinários e não como leis.

Contra o direito positivo que atende aos interesses dos proprietários dos bosques, Marx reivindicará para os pobres o direito consuetudinário, efetuando a distinção entre o que é vigente e o que é racional:

Se os direitos consuetudinários dos de cima representam costumes que vão contra o conceito de direito racional, os direitos consuetudinários dos pobres vão contra o costume do direito positivo. Seu conteúdo não se rebela contra a forma legal, e sim, ao contrário, contra a carência de forma deste. A forma da lei não se opõe a eles, e sim ainda não os reveste. (MARX, 1987, p. 255).

Marx aponta nessa trajetória como é evidente a tomada de posição a partir dos interesses das classes privilegiadas, abandonando-se qualquer consideração de caráter mais universal. Mas, apesar da clareza que imprime à sua exposição, no sentido de ilustrar concretamente o uso particular do direito em favor dos privilegiados, ele se atém a considerar este episódio como mais uma manifestação contingente do mau uso ou da má compreensão do que seja o direito, por parte dos parlamentares. 
Portanto, Marx se firma na concepção racional de direito e de Estado contra a irracionalidade que ele identifica no direito positivo enquanto fruto dos interesses privados das classes privilegiadas. A sua postura é inequívoca quanto à consideração do Estado como a instância maior da universalidade, o depositário da liberdade racional, que, como tal, não pode se curvar a interesses particulares. Diante dessa constatação, o artigo desenvolve um chamamento do Estado à sua verdade. A resposta será o fechamento da Gazeta Renana.

Esses excertos são suficientes para delinear o pensamento de Marx no momento de sua inserção no idealismo ativo através da consecução do projeto de crítica filosófica ao existente no sentido de torná-lo mais racional. A explicitação de tal projeto, realizada rigorosamente por Marx em seus artigos, dá-se até o seu limite, com o fechamento do jornal.

Rossi acredita que nesse artigo Marx já antecipa a ruptura com a concepção de Estado racional. Também outros autores, como Lukács e Cornu identificam elementos nos artigos da Gazeta Renana que configurariam um anúncio, uma progressiva evolução no sentido da ruptura com o modo idealista de reflexão e concomitante preparação do materialismo. De acordo com Chasin, isso não ocorre ainda nesse momento; ao contrário, pois os artigos da Gazeta Renana, juntamente com a tese doutoral, formam uma unidade, não obstante as diferenças de grau que Marx apresenta em relação a Hegel e aos neo-hegelianos de esquerda, que diz respeito ao contorno básico de suas reflexões, alinhadas a uma antropologia racional. O que diferencia Marx em relação ao projeto dos hegelianos de esquerda é a maior radicalidade com que assume o compromisso de cobrar racionalidade ao existente, destacando-se como um humanista ferrenho e combativo. Segundo Chasin, os elementos de aproximação que tanto Rossi, quanto Cornu e Lukács, cada um a seu modo, apresentam entre os textos dessa fase prémarxiana de Marx e os seus textos futuros,

\footnotetext{
se apreendidos como presenças reflexivas atípicas ou dissonantes, os elementos ressaltados pelos três não precisam ser contestados em sua condição de inquietações teóricas abstratas e como emergências da fina sensibilidade humanitária de Marx, sempre que contrastados com a efetiva natureza da reflexão pré-marxiana dos artigos. De fato, tais momentos não alteram a natureza do arcabouço ideal que matriza o conjunto desses escritos, nem tampouco são traços constitutivos do futuro desenvolvimento teórico de seu autor. Essa é a questão decisiva, que os três intérpretes acabam por deixar bastante obscurecida, até mesmo em face dos próprios depoimentos biográficos de Marx. Em outros termos, o que suas interpretações elidem é o advento de uma viragem radical no pensamento de Marx, que este promoveu, imediatamente a seguir, não com, mas contra a natureza do pensamento político contido em seus artigos da Gazeta Renana. (CHASIN, 2009, p. 53).
} 
Em função do enquadramento teórico no qual Marx se encontrava, pode-se dizer que ele estendeu até onde era possível o exercício da crítica filosófica visando a racionalização do mundo objetivo. Os impasses a que teria chegado nesta empreitada certamente o terão levado a um questionamento desse arcabouço teórico. Ao término de sua estada na Gazeta Renana, Marx se recolhe aos estudos, para tentar responder "às dúvidas que o assaltavam", conforme seu testemunho no prefácio de 1859 à Contribuição à crítica da economia política. O resultado é a redação da Crítica da filosofia do direito de Hegel, texto no qual se dá a ruptura com a filosofia especulativa de Hegel, a partir do desenvolvimento da indicação feuerbachiana da inversão ontológica realizada por Hegel entre o ser e predicado. Desse ponto de partida, Marx contrapõe parágrafo a parágrafo as determinações hegelianas acerca do Estado, denunciando a mistificação especulativa e se aproximando, em análises que se complementam, da essência do Estado.

A importância desse momento, reconhecida por Marx, marca a exaustão de um projeto idealista de crítica da realidade, e o início de uma nova perspectiva teórica, que se inicia exatamente pelo rompimento com a filosofia especulativa e com a ideia do Estado racional. No referido prefácio de 1859 , ele diz:

\footnotetext{
Minhas investigações me conduziram ao seguinte resultado: as relações jurídicas bem como as formas de estado, não podem ser explicadas por si mesmas, nem pela chamada evolução geral do espírito humano; estas relações têm, ao contrário, suas raízes nas condições materiais de existência, em sua totalidade, relações estas que Hegel, a exemplo dos ingleses e franceses do século XVIII, compreendia sob o nome de 'sociedade civil. Cheguei também à conclusão de que a anatomia da sociedade burguesa deve ser procurada na Economia Política. (MARX, 2003, p. 4-5).
}

Portanto, o período que engloba a tese doutoral e os artigos de 1842 a março de 1843 , no qual Marx conviveu criticamente com os jovens hegelianos de esquerda, constitui seu período juvenil. Para além dele, o autor opera uma inflexão em seu pensamento que o levará a recolocar as antinomias essência-aparência, subjetividade-objetividade, pensamento-mundo, sobre bases teóricas absolutamente distintas.

Reconhecido o seu objeto de análise - a sociedade civil -, a obra seguinte de Marx se configura como o desenvolvimento mais abrangente das relações entre as instâncias da vida social, a partir do reconhecimento da prioridade ontológica do modo de produção material, que, como indica o autor, vai muito além da produção da vida material. Momento de elaboração e amadurecimento teórico de novas categorias que procuram apreender a lógica da reali- 
dade social e a constituição contraditória do indivíduo e do gênero, sem, no entanto, deixar de ter como horizonte a potencialidade do desenvolvimento humano, presente desde seus primeiros escritos.

\section{REFERÊNCIAS}

ALTHUSSER, Louis. Marxismo e Humanismo. In: ALTHUSSER, Lois et.al. Polêmica sobre o humanismo. Lisboa: Editorial Presença, s/d.

CHASIN, José. Marx: estatuto ontológico e resolução metodológica. São Paulo: Boitempo, 2009.

COLLIN, Denis. Epicuro e a formação do pensamento de Karl Marx. POLITEIA: História e Sociedade, Vitória da Conquista, v. 6, n. 1, p. 15-27, 2006.

CORNU, Auguste. Del idealismo al materialismo histórico. Buenos Aires, Platina Stilcograf, 1965.

FOSTER, John Bellamy. A ecologia de Marx: materialismo e natureza. Rio de Janeiro: Civilização Brasileira, 2005.

HEGEL, F.G.W. Fenomenologia do espírito. Petrópolis: Vozes, 1992.

HEGEL, F.G.W. Enciclopédia das ciências filosóficas em compêndio - v. I. A ciência da lógica. São Paulo: Loyola, 2005.

LUKÁCS, Gyorg. O jovem Marx e outros escritos de filosofia. Rio de Janeiro: Editora da UFRJ, 2009.

MARX, Karl. Diferença entre as filosofias da natureza de Demócrito e Epicuro. São Paulo: Boitempo, 2018.

MARX, Karl. Escritos de juventud. México: Fondo de cultura econômica, 1987.

MARX, Karl. Contribuição à crítica da economia política. São Paulo: Martins Fontes, 2003.

PESSANHA, José Américo. Marx e os atomistas gregos. In: MARX, K. Diferenças entre as filosofias da natureza de Demócrito e Epicuro. São Paulo: Global, s/d.

ROSSI, Mario. La génesis del materialismo histórico - 2, el jóven Marx. Madrid: Alberto Corazón, 1971. 